\title{
O impacto da pandemia do COVID-19 na gestão financeira das micro e pequenas empresas do setor varejista de Cláudio-MG
}

The impact of the COVID-19 pandemic on the financial management of micro and small companies

\author{
in the retail sector in Cláudio-MG
}

El impacto de la pandemia COVID-19 en la gestión financiera de las micro y pequeñas empresas del sector retail en Cláudio-MG

Recebido: 21/04/2021 | Revisado: 05/05/2021 | Aceito: 16/05/2021 | Publicado: 02/06/2021

Fernanda Franciele Sousa Salomé
ORCID: https://orcid.org/0000-0001-9666-3375
Universidade do Estado de Minas Gerais, Brasil
E-mail: fernandafrancielly15@ @otmail.com
Raímme Mayra do Nascimento Sousa
ORCID: https://orcid.org/0000-0002-7302-0315
Universidade do Estado de Minas Gerais, Brasil
E-mail: raimmemayra@ gmail.com
Raquel Elaine Amaral de Sousa
ORCID: https://orcid.org/0000-0002-1431-4962
Universidade do Estado de Minas Gerais, Brasil
E-mail: raquelelaine1711 @ gmail.com
Valdilene Gonçalves Machado Silva
ORCID: https://orcid.org/0000-0002-7262-6438
Universidade do Estado de Minas Gerais, Brasil
E-mail: valdilenemachado@gmail.com

\section{Resumo}

O objetivo deste trabalho foi analisar o impacto da pandemia do COVID-19 na gestão financeira das micro e pequenas empresas do setor varejista de Cláudio-MG. Foi realizada uma pesquisa exploratória, com abordagem quantitativa, através de um estudo de caso das micro e pequenas empresas do setor varejista que fizeram parte da campanha "Comércio Consciente contra a COVID-19", em Cláudio-MG. As informações foram coletadas através de questionário utilizando-se o aplicativo google formulários. Identificou-se que a maioria das empresas eram preponderantemente do ramo de vestuário e atuavam no mercado entre dois e cinco anos. A gestão financeira era realizada pelos próprios empreendedores, em sua maioria do gênero feminino, atuavam na área financeira de um a cinco anos, possuíam ensino médio completo e não tinham formação na área financeira, porém, durante a pandemia alguns buscaram capacitação na área. Antes da pandemia a maior parte da amostra estava com o faturamento em crescimento, conseguiam pagar suas contas em dia e não era da prática diária das empresas a utilização sistemática de ferramentas de gestão financeira. Sendo que, as mais utilizadas eram o controle de fluxo de caixa, o controle de contas a pagar e receber, o controle de custos, o controle de estoque e realizavam vendas pelo cartão de crédito. Com a crise ocasionada pela pandemia o faturamento diminuiu e começaram a ter mais dificuldade de manter os pagamentos em dia. Uma parte delas teve aumento dos custos com pessoal, impostos, energia elétrica, entre outros. Continuaram utilizando as mesmas ferramentas empregadas antes da pandemia, porém mais empresas passaram a aplicar as mesmas. A análise da necessidade de capital de giro, que era pouco usada passou a ser utilizada pelas organizações. Portanto, os principais impactos ocasionados pela crise decorrente da pandemia sobre a maioria das empresas foram negativos, entre eles estão a queda do faturamento; a mudança na forma de funcionamento da empresa; o aumento dos gastos, principalmente com pessoal, energia elétrica, água e impostos; a demissão ou afastamento de funcionários, redução da jornada de trabalho e suspensão do contrato de trabalho; entre outros. Porém, algumas tiveram impacto positivo, considerando que houve aumento do faturamento.

Palavras-chave: Pandemia; Pequenos negócios; Gestão financeira.

\footnotetext{
Abstract

The objective of this work was to analyze the impact of the COVID-19 pandemic on the financial management of micro and small companies in the retail sector in Cláudio-MG. An exploratory research was carried out, with a quantitative approach, through a case study of micro and small companies in the retail sector that were part of the campaign "Conscious Trade Against COVID-19", in Cláudio-MG. The information was collected through a questionnaire using the google forms application. It was identified that the majority of companies were predominantly
} 
in the clothing industry and operated in the market for two to five years. Financial management was carried out by the entrepreneurs themselves, most of whom were female, worked in the financial area for one to five years, had completed high school and had no training in the financial area, however, during the pandemic some sought training in the area. Before the pandemic, most of the sample had growing revenues, were able to pay their bills on time and it was not the daily practice of companies to systematically use financial management tools. The most used ones were cash flow control, accounts payable and receivable control, cost control, inventory control and they made sales by credit card. With the crisis caused by the pandemic, revenues decreased and they began to have more difficulty in keeping payments up to date. A part of them had increased costs with personnel, taxes, electricity, among others. They continued to use the same tools used before the pandemic, but more companies started using them. The analysis of the need for working capital, which was little used, started to be used by more companies. Therefore, the main impacts caused by the crisis resulting from the pandemic on most companies were negative, among them are the drop in revenues; the change in the way the company works; the increase in expenses, mainly with personnel, electricity, water and taxes; the dismissal or removal of employees, reduced working hours and suspension of the employment contract; among others. However, some had a positive impact, considering that there was an increase in sales.

Keywords: Pandemic; Small business; Financial management.

\section{Resumen}

El objetivo de este trabajo fue analizar el impacto de la pandemia COVID-19 en la gestión financiera de las micro y pequeñas empresas del sector retail de Cláudio-MG. Se realizó una investigación exploratoria, con enfoque cuantitativo, a través de un estudio de caso de micro y pequeñas empresas del sector retail que formaron parte de la campaña "Comercio Consciente Contra COVID-19", en Cláudio-MG. La información se recopiló a través de un cuestionario utilizando la aplicación de formularios de Google. Se identificó que la mayoría de las empresas pertenecían principalmente a la industria de la confección y operaban en el mercado durante dos a cinco años. La gestión financiera la realizaban los propios emprendedores, la mayoría mujeres, laboraban en el área financiera de uno a cinco años, habían completado el bachillerato y no tenían capacitación en el área financiera, sin embargo, durante la pandemia algunos buscaron capacitarse en el área financiera. área. Antes de la pandemia, la mayoría de la muestra tenía ingresos crecientes, podía pagar sus facturas a tiempo y no era la práctica diaria de las empresas utilizar sistemáticamente herramientas de gestión financiera. Los más utilizados fueron control de flujo de caja, control de cuentas por pagar y por cobrar, control de costos, control de inventarios y realizaban ventas con tarjeta de crédito. Con la crisis provocada por la pandemia, los ingresos disminuyeron y empezaron a tener más dificultades para mantener al día los pagos. Una parte de ellos había incrementado los costos con personal, impuestos, electricidad, entre otros. Continuaron usando las mismas herramientas que se usaban antes de la pandemia, pero más empresas comenzaron a aplicarlas. El análisis de la necesidad de capital de trabajo, poco utilizado, pasó a ser utilizado por las organizaciones. Por tanto, los principales impactos provocados por la crisis derivada de la pandemia en la mayoría de las empresas fueron negativos, entre ellos la caída de los ingresos; el cambio en la forma de trabajar de la empresa; el aumento de los gastos, principalmente con personal, luz, agua e impuestos; el despido o remoción de empleados, la reducción de la jornada laboral y la suspensión del contrato de trabajo; entre otros. Sin embargo, algunos tuvieron un impacto positivo, considerando que hubo un aumento en las ventas.

Palabras clave: Pandemia; Pequeños negocios; Gestión financiera.

\section{Introdução}

Com o advento das tecnologias de comunicação, as barreiras geográficas, linguísticas e culturais deixaram de existir. Surgiu um mercado global, onde o principal concorrente de uma empresa pode estar do outro lado do mundo. Essas novas tecnologias permitiram o atendimento ágil e eficiente às necessidades do cliente, independentemente de sua localização geográfica. Com a pandemia do novo coronavírus - COVID-19, este mercado global teve que se adaptar às medidas de prevenção impostas pelos órgãos sanitários e ainda continuar comercializando seus produtos e serviços para a sobrevivência da empresa. Nessa perspectiva, as empresas de micro e pequeno porte, que ainda utilizam apenas o modelo tradicional de comercialização, a loja física, estão expostas ao grande risco de não conseguirem sobreviver à atual crise provocada pela pandemia do COVID-19, o que impõe a elas uma demanda prioritária de adaptação.

Assim, nesse processo de evolução e adaptação, as empresas que possuem uma visão clara de sua situação e principalmente dos recursos que dispõe, apresentam uma vantagem competitiva. Portanto, uma administração financeira adequada do empreendimento contribui de forma determinante para o enfrentamento sustentável da atual crise que impacta de forma sistêmica o mercado. 
A administração financeira apropriada, contribui para um controle eficiente do processo empresarial e dos recursos financeiros que a empresa dispõe, permitindo que seu gestor tome decisões mais acertadas que maximizem os resultados do negócio. No segmento das micro e pequenas empresas (MPE), a gestão financeira é de fundamental importância para a perpetuação dos negócios. Nesse sentido, a proposta deste trabalho é responder o seguinte questionamento: Qual o impacto da pandemia do COVID-19 na gestão financeira das micro e pequenas empresas do setor varejista de Cláudio-MG?

Definiu-se como objetivo geral analisar o impacto da pandemia do COVID-19 na gestão financeira das micro e pequenas empresas do setor varejista de Cláudio-MG. Especificamente os objetivos foram: conhecer o perfil das micro e pequenas empresas varejistas de Cláudio e de seus gestores financeiros; mapear como era realizada a gestão financeira das empresas antes da pandemia do COVID-19; verificar o que mudou na gestão financeira das empresas durante o período de pandemia do COVID-19 e identificar os principais desafios enfrentados pelas empresas na gestão financeira durante o período da pandemia do COVID-19.

As MPE's são reconhecidamente um segmento representativo da economia brasileira. Geralmente possuem poucos funcionários e uma estrutura de gestão familiar. De acordo com dados do Serviço Brasileiro de Apoio às Micro e Pequenas Empresas (SEBRAE, 2020), representam 99\% das organizações produtivas brasileiras, são responsáveis por 55\% da massa salarial do país, contribuem com cerca de $27 \%$ do Produto Interno Bruto (PIB) brasileiro e empregam em torno de 50\% dos trabalhadores com carteira assinada. As MPEs se destacam nos segmentos de comércio e serviços, contribuindo com aproximadamente 53\% PIB deste setor.

Com a nova pandemia do coronavírus, o mercado brasileiro foi profundamente afetado. O SEBRAE (2020) realizou um mapeamento do impacto do COVID-19 nos pequenos negócios no mês de março de 2020, quando a Organização Mundial de Saúde - OMS declarou estado de pandemia e sua disseminação no Brasil ficou mais aparente. Os resultados não foram nada promissores, com aproximadamente 12 milhões de negócios sendo afetados, atingindo mais de 46,6 milhões de pessoas. No mapeamento, foi identificado que houve uma queda de $29 \%$ na receita do comércio varejista, com os pequenos empreendimentos registrando uma queda de $69 \%$ no faturamento neste período, quando comparado a uma semana normal de vendas, sendo precedido de aumento da taxa de desemprego e procura por empréstimos. A pesquisa ainda destacou que na economia brasileira as pequenas empresas são aquelas que estão mais expostas, visto a imprevisibilidade da situação, a mudança nos hábitos de consumo de seus clientes e as restrições impostas para evitar a disseminação do vírus.

Desta forma, esta pesquisa se justifica pois pretende analisar os principais impactos ocasionados pela pandemia do COVID-19 na gestão financeira das micros e pequenas empresas do setor varejista de Cláudio/MG, o que permitirá aos empreendedores ter maior clareza sobre como o negócio está sendo afetado pela crise e fornecerá informações para análises técnicas que direcionarão ações estratégicas no intuito de minimizar os efeitos da pandemia na economia local e contribuir com a retomada dos negócios.

O artigo está estruturado em seis partes, considerando-se a introdução; na segunda sessão apresenta-se a visão de diversos autores sobre os temas relacionados, na terceira é descrita a metodologia aplicada para levantamento dos dados, na quarta faz-se a análise dos resultados obtidos, encerrando com a conclusão seguida das referências.

\subsection{Aspectos gerais e históricos do comércio varejista}

Varejo é a classificação comercial para as empresas que vendem produtos ou serviços diretamente ao consumidor final para satisfazer suas necessidades pessoais, inclui todas as atividades relacionadas à venda de produtos ou serviços, para uso pessoal e não comercial. Logo, uma empresa varejista é qualquer empreendimento cuja receita provém principalmente da venda de pequenos lotes no comércio, não sendo influenciado pelo canal em que a venda ocorre, seja pessoalmente, por 
correio, por telefone, máquinas de venda automática, internet, loja, nas ruas, na casa do consumidor e assim por diante (Kotler \& Keller, 2006).

O mesmo autor ainda destaca que os varejistas podem se posicionar para oferecer um dos quatros níveis de serviços: 1) Autoatendimento: para gastar menos, as pessoas estão prontas para pesquisar, comparar e selecionar itens. 2) Seleção: os clientes encontram os produtos que desejam comprar, mas podem pedir ajuda. 3) Serviço limitado: os produtos mais vendidos estão em exibição e as pessoas precisam de informações e ajuda. Nesse tipo de comércio, o cliente tem privilégios de crédito e devolução de produto. 4) Serviço abrangente: os comerciantes da planta estão prontos para auxiliar os clientes em todas as etapas do processo, ou seja, pesquisa, comparação e seleção. Aqui as pessoas gostam de ser cuidadas pessoalmente, porém, o alto custo com pessoal, aliado ao maior número de produtos especializados e menos móveis, resulta em uma espécie de comércio de alto custo.

O varejo é um processo recorrente ao longo da história da civilização. Há registros que este modelo de comércio se desenvolveu juntamente com a organização da vida em sociedade, iniciando pelas formas primitivas de escambo. Sua disseminação para o mundo foi influenciada pelas grandes movimentações financeiras de Atenas e Roma, os grandes centros comerciais da época que possuíam negócios com outras regiões, passando pela evolução mercantilista que envolvia as primeiras trocas monetárias, até chegar às formas de comercialização modernas com a utilização de dinheiro, talões de cheques, cartões de créditos, transações eletrônicas, entre outros (Donato, 2012).

Com o passar do tempo, o mercado foi se tornando cada vez mais complexo, aumentando os desafios para gerenciamento dos negócios. A partir da década de 1980, Lima Filho et al. (2006) destaca que o mercado evoluiu a operacionalização dos recursos do varejo, com as empresas tomando ciência de que levaria tempo, recursos e ferramentas para se preparar para atender as necessidades dos clientes, mas se não colocassem os consumidores no centro de seus negócios, não conseguiriam manter a empresa operante a longo prazo.

No Brasil, em um ambiente macroeconômico com negócios fragilizados e um perfil empresarial pouco familiarizado com a tomada de decisões baseadas na informação, tem sido uma tarefa desafiadora se adaptar ao mercado digital. Essa perspectiva foi apresentada na pesquisa Desafios do Varejo, realizada pela Confederação Nacional de Dirigentes Lojistas (CNDL), pelo Serviço de Proteção ao Crédito (SPC Brasil) e pelo Serviço Brasileiro de Apoio às Micro e Pequenas Empresas SEBRAE (Viana, 2019).

Um levantamento da Agência IBGE Notícias (2020) evidenciou que cinco das oito atividades que integram o comércio varejista registraram recuo nas vendas em junho de 2019 em comparação junho do ano anterior. As perdas ocorreram nos segmentos de móveis e eletrodomésticos (-6,5\%), tecidos, vestuário e calçados (-1,1\%). Outros artigos de uso pessoal e doméstico (-0,8\%), equipamentos e material para escritório, informática e comunicação $(-8,8 \%)$ e livros, jornais, revistas e papelaria $(-26,2 \%)$. Em contrapartida, a pesquisa apontou que os segmentos varejistas que atendem às necessidades básicas registraram aumento no mesmo período como, por exemplo, artigos farmacêuticos, médicos, ortopédicos, de perfumaria e cosméticos (5\%), hipermercados, supermercados, produtos alimentícios, bebidas e fumo (0,7\%) e combustíveis e lubrificantes (0,5\%) (Agência IBGE Notícias, 2020).

Ayer (2019) destaca que o varejo vem apresentando crescimento inferior, alinhado com a falta de dinamismo na recuperação econômica e o endividamento das famílias. Esse panorama afeta principalmente as micro e pequenas empresas varejistas, que apesar de serem um dos destaques da economia brasileira na contribuição para o PIB brasileiro, sofrem maior exposição aos riscos sistêmicos do mercado. 


\subsection{As MPEs e sua importância para o crescimento socioeconômico}

Segundo SEBRAE (2014), as empresas podem ser classificadas de acordo com o número de pessoas ocupadas sendo classificadas como Microempresa aquelas com até 9 pessoas ocupadas, tanto para serviços como para o comércio ou até 19 pessoas ocupadas para indústria; como Pequena Empresa as que possuem de 10 a 49 pessoas ocupadas para serviços e comércio ou de 20 a 99 pessoas ocupadas para indústria; como Média Empresa aquelas que têm de 50 a 99 pessoas ocupadas para serviços e comércio ou de 100 a 499 pessoas ocupadas para indústria e como Grande Empresa aquelas que possuem acima de 100 pessoas ocupadas para serviços e comércio ou acima de 500 pessoas ocupadas para indústria.

No Brasil, as micro e pequenas empresas estão sendo cada vez mais reconhecidas no cenário econômico e são responsáveis por gerar o maior número de empregos formais no país. O setor apresenta, especialmente nos últimos anos, números expressivos de crescimento, consistentes com os indicadores de modernização e avanço do mundo (ADVFN, 2020).

No comércio, as pequenas empresas responderam, em 2017, por 45,5\% da receita operacional líquida de $\mathrm{R} \$ 3,4$ trilhões do comércio nacional, contra 44,6\% do setor atacadista e 9,9\% do comércio de veículos, peças e motocicletas. Já em dezembro de 2019, as vendas do comércio varejista variaram $0,1 \%$ em relação a novembro do mesmo ano, interrompendo sete meses consecutivos de crescimento, período que acumulou crescimento de 3,5\%. A média trimestral demonstrou uma desaceleração, com variação de $0,2 \%$ no trimestre e, ainda que tenha diminuído, o comércio varejista em 2019 cresceu 2,6\% em relação a 2018 (IBGE, 2019).

Em Cláudio-MG, a Sala do Empreendedor é uma parceria entre a Prefeitura Municipal e o SEBRAE, cujo objetivo é fornecer orientação aos empreendedores da região para impulsionar o desenvolvimento econômico e do empreendedorismo. De acordo com dados fornecidos por esta instituição, o munícipio de Cláudio possui 3.467 empresas ativas, sendo $61 \%$ Microempreendedor Individual, 13\% Microempresa, 5\% Empresa de Pequeno Porte e 21\% divido entre Empresas de Médio e Grande Porte, sendo, 49,78\% delas do setor de serviços, 49,64\% do comércio e 0,58\% eram indústrias (Sala do Empreendedor, 2020).

Para Viana (2019), os últimos anos talvez tenham sido os mais dramáticos da economia brasileira. Os chamados "anos de ouro" (época em que aconteceram revoluções tecnológicas) ficaram para trás e já se fala em "nova década perdida", comparando com os anos 80 (um período em que o Brasil passou por uma crise econômica, com inflação e queda no Produto Interno Bruto - PIB). Contudo, para o segmento de varejo, liderado pelas pequenas empresas, os especialistas apontam resiliência, eficiência, produtividade e transformação. $\mathrm{O}$ mesmo autor ainda complementa que as empresas menos preparadas terão suas atividades encerradas, como é natural em um período turbulento e de mudanças rápidas, entretanto, com esse novo espaço, surgirão novas empresas, mais bem preparadas e predispostas a inovar de maneira ágil. Sendo assim, nesse cenário, onde sobrevive aquela que melhor se adapta as mudanças, um dos fatores que pode contribuir favoravelmente para a sobrevivência e longevidade das organizações é uma gestão financeira eficiente.

\subsection{Gestão Financeira}

Segundo Junqueira (2018), realizar a gestão financeira é uma das principais atividades do negócio, afinal é através dos indicadores financeiros que o gestor tomará ciência da situação da empresa e conseguirá traçar estratégias para atingir os objetivos a que se propôs.

Para Gitman (2010, p. 27), a gestão financeira pode ser entendida "como a arte ou ciência de administrar dinheiro". A área de finanças preocupa-se com "processos, instituições, mercados e instrumentos envolvidos na transferência de dinheiro entre pessoas, empresas e órgãos governamentais.” (Ibidem, p. 3).

O alinhamento dos processos do negócio é de grande importância para que a empresa trabalhe de forma eficiente e consequentemente atenda às necessidades dos consumidores. Através de uma gestão financeira adequada, o administrador é 
capaz de visualizar a situação da empresa e identificar os pontos a serem aprimorados, além de estabelecer rotinas integradas para minimizar erros operacionais que afetam a produtividade e a lucratividade (Junqueira, 2018).

Nos negócios, a conciliação das metas estabelecidas com as restrições financeiras gera um grande desafio para o gestor, que deve desenvolver estratégias que atinjam os resultados esperados dentro das condições financeiras da empresa. Portanto, a maior eficiência e produtividade do negócio deve ser buscada continuamente (Kummer et al., 2011).

A utilização de um sistema de informação gerencial favorece a centralização das informações do negócio e contribui para apresentar um panorama mais realista, permitindo ao gestor identificar as barreiras que dificultam o crescimento da empresa, para que medidas corretivas eficazes sejam implementadas em tempo (Junqueira, 2018).

Para Antonik (2016) a administração financeira pode ser exercida por meio de diversos tipos de ferramentas. Entre os mais utilizados pelas empresas, principalmente pelos micros e pequenos negócios, se encontra o controle de custos, do fluxo de caixa, da inadimplência, das contas a pagar e receber, do capital de giro, como também a análise da capacidade de crédito e da demonstração de resultado do exercício, entre outras. O mesmo autor ainda afirma que o controle de custos é uma das ferramentas mais simples de implementar na empresa e é inerente a própria existência do negócio. Podendo ser realizado de maneira manual ou através de sistemas informatizados, registra e controla as saídas, permitindo verificar o histórico de custos, alinhar novas estratégias de compras, identificar pontos frágeis na organização e auxiliar na formação do preço de venda.

O controle do fluxo de caixa é uma das principais ferramentas de controle financeiro. Identificando as movimentações financeiras, a liquidez do negócio e as necessidades de recursos, auxilia o gestor a verificar a sustentabilidade e a capacidade de pagamento da empresa, permitindo realizar as correções e adequações necessárias (Gitman, 2010).

Para Assaf Neto e Lima (2014), o capital de giro é representado pelo ativo circulante, constituído pelas disponibilidades, valores a receber e estoque, que são os recursos financeiros necessários ao financiamento de suas operações diárias, ou seja, para que a organização possa cumprir com suas obrigações até a data do vencimento. O autor ainda destaca a importância de uma gestão eficiente do capital giro para assegurar a saúde financeira da empresa, alegando que a sua gestão ineficiente pode levar o empreendimento a uma situação de insolvência e consequentemente ao encerramento precoce das atividades. Existem algumas ferramentas que permitem a análise do capital de giro de forma mais criteriosa, entre elas estão o Capital Circulante líquido - CCL, que permite verificar quais são as fontes de financiamentos do ativo circulante. A Necessidade de Investimento em Giro - NIG que permite a identificação das fontes de financiamento do ativo circulante operacional e o Saldo de Tesouraria - ST, que é o termômetro dos riscos decorrentes da falta de sincronização entre os ativos e passivos circulantes financeiros (Hoji, 2014).

Outros dois pontos importantes na gestão do capital de giro são a gestão de estoques e de contas a receber. A gestão de estoque tem o objetivo de manter os níveis de estoque o mais baixo possível para, assim, girá-los mais rápido, para que o investimento de capital de giro em estoque seja o menor possível, porém sem perder vendas por falta de estoque. A proposta da gestão de contas a receber é cobrar os valores a receber o mais rápido possível, sem perder vendas devido ações muito severas de cobrança, a intenção é ter o menor investimento possível em contas a receber (Gitman, 2010).

A Demonstração de Resultado do Exercício - DRE é um importante demonstrativo para análise do desempenho e da saúde financeira da empresa, pois "fornece um resumo financeiro dos resultados operacionais da empresa durante um determinado período." (Gitman, 2010, p. 41). Suas informações podem ser transformadas em indicadores para análises e tomada de decisões mais seguras.

Antes da pandemia do COVID-19, a gestão financeira já possuía grande importância para a sobrevivência da empresa, principalmente para as MPE's. A partir de 2020, a administração financeira nunca foi tão essencial para auxiliar o gestor a entender melhor o negócio, e, assim, tomar decisões mais seguras. Considerando que, além de atender as necessidades dos consumidores, a empresa também deverá se adaptar às orientações para prevenção do COVID-19, ao isolamento social para 
mitigar a disseminação do vírus, lidar com surgimento de novos concorrentes, se estruturar para se proteger das novas ameaças, bem como aproveitar as novas oportunidades oferecidas pelo mercado para crescimento. Assim, mais do que do fornecer um diagnóstico do negócio, os gestores financeiros também deverão se posicionar estrategicamente em relação aos impactos a curto e longo prazo das variáveis micro e macro ambientais sobre o empreendimento.

\subsection{O impacto da pandemia do COVID-19 no comércio varejista}

A pandemia ocasionada pelo novo coronavírus expôs o mercado brasileiro a um desafio sem precedentes. No relatório Covid-19 no Brasil: impactos e respostas de políticas públicas, elaborado e disponibilizado pelo Banco Mundial indicou que o país estava se recuperando da recessão econômica de 2015/16, quando a pandemia gerou dois novos choques: o internacional que envolvia a demanda e preços externos e um choque interno devido ao isolamento que influenciou na oferta e na demanda e as restrições impostas à comercialização para conter o contágio (Banco Mundial, 2020).

Nesse cenário de recessão, estimativas do Banco Mundial (2020) sugerem que as micro e pequenas empresas serão as mais afetadas, visto que, na maioria dos casos, suas atividades econômicas requerem interação pessoal, como varejo, hotelaria, turismo e outras. Outro fator preocupante destacado foi que, devido à baixa reserva de caixa que normalmente essas empresas possuem, necessitam de muitos investimentos em capital de giro para manter a liquidez mesmo sem rendimentos. No estudo, é apontado que de $39 \%$ a $56 \%$ das micro, pequenas e médias empresas terão reservas de caixa para suportar até 21 dias de isolamento, caso não consigam se adaptar para continuar a comercialização.

A Confederação Nacional do Comércio de Bens, Serviços e Turismo (CNC) realizou estudo com o objetivo de avaliar o impacto das estratégias adotadas para conter o desenvolvimento da pandemia. O estudo indicou que o segmento de varejo teve uma perda de $\mathrm{R} \$ 86,4$ bilhões em receita entre 15 de março e 18 de abril de 2020, ficando 39\% abaixo do que foi confirmado no mesmo período de 2019. Em função disso, foi previsto 2,2 milhões de perdas de empregos no comércio nos próximos 3 meses, com as maiores perdas concentradas nos segmentos de varejo de produtos não essenciais (Exame, 2020).

De acordo com Stanley (2020), citado por Bomfim (2020), haverá um declínio de $70 \%$ a $80 \%$ nas vendas de eletrônicos e vestuário no segundo trimestre de 2020, com uma normalização parcial no terceiro trimestre. Por outro lado, o crescimento nas vendas de alimentos vai contrabalancear essas perdas. No cenário-base, é previsto crescimento de $24 \%$ para o e-commerce, com avanço de $16 \%$ no segundo trimestre. A restauração do varejo pós-quarentena será gradativa, diz Bomfim (2020), pois ainda haverá o temor de consumir em locais públicos como shoppings e restaurantes, com menor renda disponível devido ao aumento do desemprego.

No relatório do Banco Mundial, a perspectiva da recuperação do varejo pós-quarentena no Brasil se baseia na expectativa de crescimento de $2,2 \%$ em 2021, caso o país consiga reduzir a propagação do vírus e a agenda pública priorize o apoio à liberação de crédito, fortalecendo a tributação dos entes subnacionais e apoio às empresas e ao emprego, com vista à recuperação desigual dos postos de trabalho, visto que alguns segmentos vão continuar a sofrer a médio e longo prazo ou vão encolher permanentemente como uma nova forma de lidar com o cliente e comercializar. O relatório comenta que o Banco Central e o governo introduziram um pacote de apoio ao setor financeiro e às médias, pequenas e micro empresas para manter empregos e, assim, garantir a renda familiar dos brasileiros (BANCO MUNDIAL, 2020). O pacote inclui "medidas de apoio à liquidez, diferimento de impostos, medidas trabalhistas para compensar os salários e tornar os contratos mais flexíveis e aliviar os encargos regulamentares" (Ibidem, p. 16).

A união entre governo e Banco Central tem o propósito de garantir a sustentabilidade do sistema financeiro a médio e longo prazo, protegendo o país do círculo vicioso de liberação de empréstimos e aumento da inadimplência, o que leva à insolvência de empresas. 


\section{Metodologia de Pesquisa}

$\mathrm{O}$ universo de estudo foram as micro e pequenas empresas varejistas que aderiram à campanha "Comércio Consciente contra a COVID-19", do município de Cláudio-MG. Em um primeiro momento a campanha buscou despertar nos gestores das empresas a necessidade de minimizar os impactos da pandemia no comércio regional. No segundo momento, a campanha teve o objetivo de repassar as informações para os colaboradores das empresas. A campanha à época da pesquisa se encontrava na terceira fase, estava promovendo ações de conscientização dos clientes e da comunidade claudiense sobre a importância da prevenção para evitar a propagação do COVID-19.

O presente estudo teve o objetivo de analisar o impacto da pandemia do COVID-19 na gestão financeira das micro e pequenas empresas varejistas de Cláudio-MG. Classifica-se quanto aos objetivos como a exploratória, pois, apesar do tema gestão financeira ser um tema bastante estudado, a pandemia do COVID-19 é um fato recente e não se tem ainda muitos estudos sobre o impacto do fenômeno sobre a gestão financeira das micro e pequenas empresas, especialmente no município de Cláudio. Segundo Vergara (1998), a pesquisa exploratória é realizada em área na qual há pouco conhecimento acumulado e sistematizado. Por sua natureza de sondagem, não comporta hipóteses que, todavia, poderão surgir durante ou ao final da pesquisa.

Quanto aos procedimentos se classifica como estudo de caso, pois a intenção foi realizar um estudo em profundidade sobre o impacto causado pela pandemia do COVID-19 na gestão financeira das empresas varejistas que participaram da campanha “Comércio Consciente contra a COVID-19” em Cláudio-MG. De acordo com Gil (2008, p. 57-58), “O estudo de caso é caracterizado pelo estudo profundo e exaustivo de um ou de poucos objetos, de maneira a permitir o seu conhecimento amplo e detalhado (...).”

Quanto à abordagem foi quantitativa, pois buscou-se quantificar em números os impactos da pandemia nas finanças das empresas pesquisadas. De acordo com Prodanov e Freitas (2013), a pesquisa quantitativa considera que tudo pode ser quantificado, o que significa traduzir informações em números, para classificá-las e analisá-las. Requer o uso de recursos e de técnicas estatísticas, como cálculo de percentagem, média, desvio-padrão, análise de regressão entre outros.

$\mathrm{O}$ universo de pesquisa foram as 118 empresas, que fizeram parte da campanha "Comércio Consciente contra a COVID-19” em Cláudio-MG. A amostra foi definida por acessibilidade, ou seja, foi enviado o link para responder o questionário para todas as empresas que compunham o universo pesquisado e a amostra foi constituída por todas as empresas que responderam a pesquisa, perfazendo um total de 61 empresas, que representaram 51,69\% do universo. Na amostragem por acessibilidade, segundo Gil (2008, p. 94), "O pesquisador seleciona os elementos a que tem acesso, admitindo que estes possam, de alguma forma, representar o universo."

Utilizou-se como instrumento de coleta de dados o questionário que foi elaborado com 32 perguntas de múltipla escolha, agrupadas em blocos, pautando-se pelos objetivos propostos, para melhor organização da pesquisa. Assim, o bloco I tratou do perfil da empresa e de seus gestores; o bloco II das práticas de gestão utilizadas pela empresa antes do período da pandemia do COVID-19; o bloco III, dos desafios enfrentados pelas empresas na sua gestão financeira durante o período da pandemia do COVID-19; e, finalmente, o bloco IV abordou as principais mudanças ocorridas na gestão financeira das empresas durante o período de pandemia do COVID-19.

Para elaboração do questionário utilizou-se a plataforma Google Formulários, cujo link de acesso ao questionário para resposta, após o pré-teste, foi encaminhado, pela gestora da campanha, por e-mail e Whatsapp para todas as empresas que compunham o universo pesquisado. Os dados levantados foram tratados com auxílio do aplicativo Microsoft Excel ${ }^{\mathrm{R}} \mathrm{e}$ transformados em gráficos para análises e conclusões.

Os resultados deste trabalho serão apresentados às empresas com o objetivo de contribuir na formulação de estratégias que as auxiliem na recuperação da crise e a se fortalecerem neste novo cenário, ainda mais competitivo. 


\section{Resultados e Discussão}

No intuito de identificar os impactos da pandemia do COVID-19 na gestão financeira das micro e pequenas empresas do setor varejista da cidade de Cláudio-MG foi realizada uma pesquisa, com abordagem quantitativa, no período de Dezembro/2020 a Janeiro/2021, com as empresas que fizeram parte da campanha "Comércio Consciente contra a COVID-19".

$\mathrm{Na}$ pesquisa, o primeiro bloco de perguntas foi para conhecer o perfil das empresas e de seus gestores. Identificou-se que $24,59 \%$ delas eram do setor de vestuário, $16,39 \%$ eram do segmento de alimentação com venda direta ao consumidor, $13,11 \%$ do setor calçadista, $6,56 \%$ são farmácias, 4,92\% eram academias, 4,92\% padarias, 4,92\% empresas de móveis e decoração, 4,92\% eram supermercados, 4,92\% papelarias, 3,28\% floriculturas, 3,28\% sorveterias, 1,64\% óticas, 1,64\% mercearias, $1,64 \%$ bijuterias, $1,64 \%$ perfumaria e 1,64\% eletrodomésticos.

Sobre o tempo de atuação no mercado, 39,34\% das empresas estavam no mercado entre 2 e 5 anos, 16,39\% atuavam entre 5 e 10 anos, $14,75 \%$ entre 10 e 15 anos e 29,51\% das empresas tinham mais de 15 anos de atuação no mercado.

Em relação ao perfil do gestor financeiro, verificou-se que 62,30\% dos responsáveis pela gestão financeira das empresas eram os próprios empreendedores, $29,50 \%$ eram funcionários e 8,20\% eram gerentes. Em relação ao tempo de exercício da função, 55,32\% estavam na função de 1 a 5 anos, 14,89\% de 5 a 10 anos, 10,64\% de 10 a 15 anos e 19,15\% há mais de 16 anos.

Quanto ao gênero dos gestores financeiros, 63,93\% eram do gênero feminino e 36,07\% do masculino. Com referência ao grau de instrução, os resultados apontaram que 8,20\% da amostra possuía apenas ensino fundamental, 36,07\% tinham o Ensino Médio completo, 18,03\% o ensino superior incompleto, 24,59\% o ensino superior completo e 13,11\% tinham pósgraduação. Do grupo que possuía ensino superior completo e pós-graduação, apenas 21,31\% possuíam formação em áreas que abordavam Gestão Financeira como Administração, Economia e Ciências Contábeis, e 78,69\% possuíam formação em outras áreas. Sobre a formação complementar relacionada a gestão financeira, 22,95\% participaram de programas e consultorias sobre o tema, 14,75\% participaram de cursos de curta duração (até 40h), 6,56\% possuía curso de pós graduação em Gestão Financeira, 3,28\% possuía outras formações e 52,46\% não possuía formação na área.

Portanto, observou-se que as empresas pesquisadas eram predominantemente do ramo de vestuário e relativamente jovens, pois a maioria estava no mercado entre 2 e 5 anos. A gestão financeira era realizada principalmente pelos próprios empreendedores, que atuavam na função entre um e cinco anos, que é o mesmo tempo de existência das empresas. Os gestores financeiros eram, em sua maioria, do gênero feminino, possuíam ensino médio completo e não tinham formação na área financeira. A baixa escolaridade e falta de formação na área financeira dos gestores financeiros é uma fragilidade das empresas pesquisadas, pois, a falta de conhecimento em finanças conduz a uma gestão financeira frágil já que, seus gestores, por não conhecerem, não tomam decisões baseadas em informações seguras, que são fornecidas pelos controles e demonstrativos financeiros e, também, não utilizam ferramentas que podem otimizar a aplicação dos recursos financeiros, tornando a empresa mais lucrativa, com maior liquidez e, portanto, mais competitiva. Nesse sentido, Marion (2009, p. 26) destaca que a gerência ineficiente e a tomada de decisões sem respaldo dos indicadores da empresa são um dos principais fatores que contribuem para aumentar os índices de mortalidade das empresas. A administração inadequada, por vezes, é causada pela falta de conhecimento e experiência do gestor, que empreende em busca de oportunidades, contudo não se capacita para fazer frente as demandas do negócio e do mercado em que atua.

O segundo bloco do questionário foi para identificar as práticas de gestão financeira utilizadas pelas empresas antes do período da pandemia do COVID-19. Apurou-se que o faturamento de 75,41\% das empresas estava em crescimento, 21,31\% estavam com o faturamento estável e de $3,28 \%$ o faturamento estava diminuindo. Sobre se as empresas estavam conseguindo pagar suas contas em dia, identificou-se que $83,61 \%$ delas não tinham inadimplência, ou seja, estavam, com pagamento das contas em dia. Apesar da grande maioria afirmar que não possuía inadimplência, uma parte significativa (11,47\%) delas 
estavam com dificuldades financeiras. Um fator que chamou a atenção foi que 4,91\% não tinham controle de contas a pagar. Estas dificuldades podem ser decorrentes da não utilização de ferramentas adequadas à realidade da empresa para uma gestão financeira eficiente, como o controle de contas a pagar, que de acordo com Oliveira (2013, p. 25), "Estabelece prioridades de pagamento em caso de dificuldades financeiras; controla o montante dos compromissos já vencidos e não pagos, e, em casos de dificuldades financeiras; fornece informações para elaboração de fluxo de caixa."

Sobre as ferramentas utilizadas na gestão financeira do negócio (Gráfico 1) foi identificado que as mais utilizadas eram controle do fluxo de caixa $(15,21 \%)$, controle de contas a pagar e receber $(13,31 \%), 8,37 \%$ realizavam vendas a prazo no cartão de crédito, 7,98\% faziam controle dos custos, 7,22\% realizam controle de estoque e 5,32\% faziam controle da inadimplência. Nesta pergunta do questionário, as empresas puderam apontar mais de uma ferramenta que utilizavam para realizar a gestão financeira.

Gráfico 1 - Ferramentas utilizadas na Gestão Financeira antes da Pandemia.

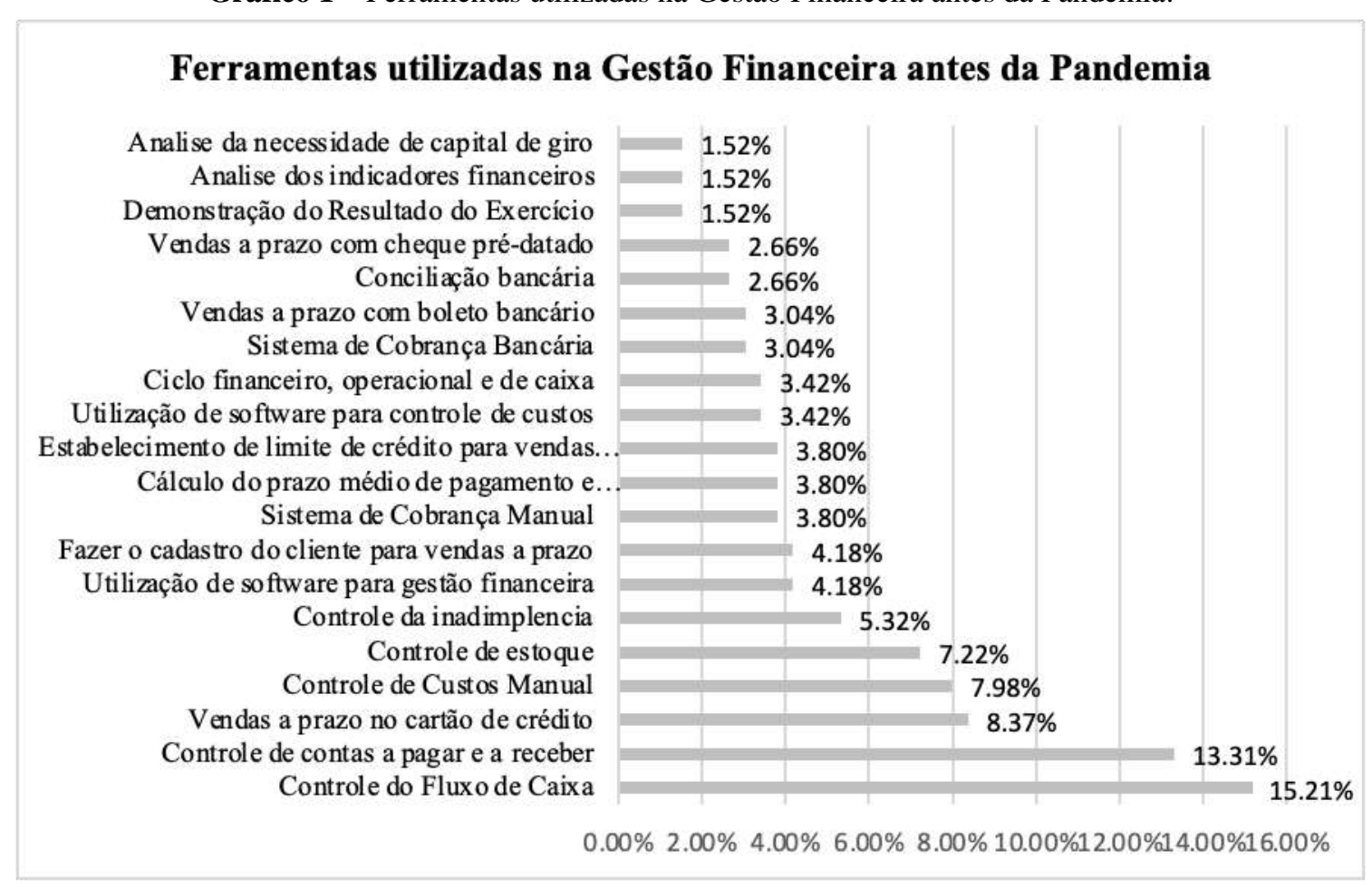

Fonte: Autores (2021).

Estas informações demonstram claramente a falta de conhecimento de seus gestores financeiros sobre finanças, como já identificado no primeiro bloco de perguntas. Por não terem conhecimento, deixam de utilizar ferramentas importantes para uma gestão financeira eficaz. Ferramentas básicas, porém, fundamentais para uma gestão financeira adequada não são utilizadas pela maioria das empresas pesquisadas, o que pode comprometer a sua lucratividade e liquidez, colocando em risco a sua sobrevivência. O fluxo de caixa, que é a ferramenta mais utilizada pelas empresas, porém apenas 15,21\% utilizavam, é uma das principais ferramentas para controle da liquidez da empresa. De acordo com Sebrae (2017, p. 1), "Fluxo de caixa é uma ferramenta de controle financeiro que mostra, detalhadamente, os valores que entram e saem de uma empresa e seu cálculo é feito a partir dos saldos existentes em contas bancárias e dinheiro disponível na empresa.” O autor ainda destaca que, através dele a empresa assegura uma vida financeira organizada, sendo que, o seu desconhecimento ocasiona a perda do controle financeiro, e, portanto, compromete a sua liquidez, o que pode implicar no encerramento precoce das atividades da empresa, se não for resolvida rapidamente. 
Cabe destacar também que as ferramentas menos utilizadas eram a análise do capital de giro (1,52\%), a análise dos indicadores financeiros $(1,52 \%)$ e a demonstração de resultado do exercício (1,52\%). Na opinião de Gitman (2010, p. 41), a Demonstração de Resultado do exercício "Fornece uma visão financeira sintética dos resultados das operações da empresa durante um período determinado.", sendo que "Os índices financeiros permitem que os administradores financeiros monitorem a saúde do negócio e seu progresso em direção a objetivos estratégicos." (Ibidem, 68). O propósito da administração do capital de giro é "Gerenciar cada elemento do ativo circulante (...) e de seu passivo circulante (...) para atingir um equilíbrio entre rentabilidade e risco que contribua positivamente para o valor da empresa." (Gitman, 2010, p. 546). Desta forma, estas ferramentas são fundamentais para uma gestão eficaz. Portanto, as empresas pesquisadas deixavam de utilizar ferramentas importantes para uma gestão financeira que contribuísse para assegurar a liquidez, a rentabilidade do capital investido e a sua lucratividade, além de melhorar o perfil de crédito e solvência, ou seja, a otimização da utilização dos recursos financeiros. Portanto, a não utilização destas ferramentas era uma fragilidade da gestão financeira desses empreendimentos. Mannarelli Filho e Mannarelli (2020), em seu estudo, apontaram que a empresa estudada também foi fortemente impactada pela crise econômica decorrente da pandemia e, assim, necessitava implementar ferramentas gerencias para conseguir sobreviver frente aos novos desafios impostos pela crise, além de se reposicionar estrategicamente.

As perguntas do terceiro bloco foram direcionadas para identificar os desafios enfrentados pelas empresas na sua gestão financeira durante o período da pandemia do COVID-19. Apurou-se que 52,46\% dos empreendimentos tiveram que mudar o funcionamento do negócio em função da pandemia, 39,34\% continuaram a funcionar normalmente e $8,20 \%$ interromperam temporariamente suas atividades. Em relação ao faturamento mensal, em 47,54\% o faturamento diminuiu, em $22,95 \%$ aumentou, em 18,03\% permaneceu igual, $8,20 \%$ não quis informar e 3,28\% não sabia se houve alguma alteração no faturamento.

Percebeu-se que, em relação ao impacto da pandemia no faturamento das empresas, para uma parte significativa delas (47,54\%) o impacto foi negativo, pois houve redução, porém, para um outro grupo menor $(22,95 \%)$ o impacto foi positivo, considerando que houve aumento do faturamento. Outro fator que chamou a atenção foi que 3,28\% delas não tinham controle sobre o faturamento da empresa, pois não souberam informar se ele aumentou ou diminuiu. Este é mais um indicador de que a falta de conhecimento em finanças compromete o controle financeiro da empresa. A redução do faturamento pode estar relacionada ao fato de que os consumidores das micro e pequenas empresas geralmente se encontram apenas na região da empresa. De acordo com a Global Entrepreneurship Monitor - GEM (2019), mesmo com as tecnologias e a diminuição das barreiras de comunicação, mais de $90 \%$ dos negócios focam em atender apenas a demanda local, o que expõe ainda mais as organizações as crises do mercado e, em um cenário de pandemia, que impõe às pessoas o isolamento social, o faturamento dos empreendimentos fica comprometido.

Sobre o comportamento dos custos e despesas do negócio durante o período de pandemia, a pesquisa indicou que os principais aumentos ocorreram nos gastos com pessoal (24\%), com energia elétrica (17,34\%), com impostos (13,33\%), com água (12\%), com empréstimos e dívidas $(10,67 \%)$, com aluguel $(8 \%)$, com internet $(5,33)$ e com outros custos e despesas $(9,33 \%)$. Em relação aos gastos com os colaboradores, que foi o que mais aumentou durante a pandemia, a pesquisa indicou que 39,34\% dos negócios não tomaram medidas relacionadas a demissão ou afastamento, 18,03\% aplicaram medidas de redução da jornada de trabalho com redução de salários, $18,03 \%$ optaram pela suspensão do contrato de trabalho dos colaboradores, 11,48\% concederam férias coletivas e 13,11\% tomaram outras medidas que não foram colocadas como opção de resposta. O aumento dos gastos com pessoal (24\%) pareceu um pouco incoerente, considerando que 18,03\% das empresas adotaram medidas de redução da jornada de trabalho com redução de salários e 18,03\% optaram pela suspensão do contrato de trabalho dos colaboradores. O aumento dos impostos $(13,33 \%)$ pode ser justificado pelo aumento de faturamento de uma parte das empresas (22,95\%). Porém, é importante considerar que, como forma de diminuir o impacto econômico durante a 
pandemia, o Governo buscou formas para auxiliar as empresas criando um conjunto de medidas como prorrogação do pagamento dos tributos do Simples Nacional, adiamento do PIS, Pasep, Cofins e da contribuição previdenciária, redução do IOF sobre operações de crédito, prorrogação do prazo de entrega da declaração do Imposto de Renda, prorrogação da validade de certidões de débitos e créditos tributários, prorrogação de parcelamentos tributários (Alvarenga, 2020). O SEBRAE (2020) destaca que o aumento das despesas representa um grande desafio para o gestor na realização do diagnóstico e consequentemente na adaptação do planejamento financeiro. Organizações que possuem uma gestão frágil com controles financeiros deficientes podem apresentar dificuldades para se enquadrarem nos incentivos públicos oferecidos ou então não se mobilizarem para aproveitá-los, caso não tomem conhecimento das medidas ou julguem complexo o processo de solicitação. Acredita-se que essa tenha sido a realidade vivenciada pelas empresas pesquisadas.

Foi interesse da pesquisa também saber se houve alguma redução de custos e despesas durante o período da pandemia. Apurou-se que para 58,57\% das empresas não houve redução em nenhum dos gastos, houve redução do aluguel para 14,29\%, dos custos de pessoal para 11,43\%, dos custos com empréstimos e dívidas para 7,14\%, dos impostos para 4,29\%, de energia elétrica para 2,86\% e de água para 1,43\%. Entende-se que a redução desses gastos para algumas das empresas que participaram da pesquisa foi ocasionada por renegociação de dívidas e de algumas despesas, como o aluguel, funcionários, entre outras, em virtude da aderência aos incentivos do Programa Emergencial de Manutenção do Emprego e da Renda, conforme medida provisória $\mathrm{n}^{\circ} 936$, de $1^{\circ}$ de abril de 2020.

Como a pandemia do novo coronavírus trouxe vários desafios para os negócios, esta pesquisa buscou conhecer quais foram os principais desafios enfrentados pelas empresas no período. $\mathrm{O}$ maior desafio apontado por elas foi se adequarem as medidas de prevenção a disseminação do novo coronavírus impostas pelos governos $(24,27 \%)$. O segundo maior desafio foi administrar a queda do faturamento $(21,85 \%)$, o terceiro foi adaptar o negócio para oferecer o atendimento não presencial $(14,29 \%)$, em quarto foi pagar as contas em dia $(12,61 \%)$, em quinto lugar foi fazer a gestão financeira do negócio $(9,24 \%)$ e em sexto lugar obteve-se 3 apontamentos com a mesma porcentagem: aumento da inadimplência $(5,88 \%)$, demissão de funcionários $(5,88 \%)$ e a empresa se comunicar com os clientes $(5,88 \%)$. Pode-se verificar que parte das dificuldades vivenciadas pelas empresas pesquisadas também são enfrentadas por empresas de todo o Brasil. Uma pesquisa realizada pela Associação Brasileira de Comunicação Empresarial - ABERJE que identificou que os maiores desafios enfrentados pelas empresas brasileiras neste cenário de pandemia estão relacionados ao engajamento dos funcionários, proteção da saúde financeira e evoluir de maneira ágil para atender ao novo perfil do consumidor (Salomão, 2020).

Sobre as principais mudanças ocorridas na gestão financeira das empresas durante o período de pandemia do COVID19, os resultados indicaram que nesse período $34,42 \%$ delas estava utilizando os benefícios disponibilizados pelo governo e/ou instituições (agentes financeiros, SEBRAE, etc), para dar continuidade às suas atividades, 11,48\% disseram que pretendem utilizar os incentivos disponibilizados se a situação perdurar em 2021, 54,1\% das empresas informaram que não pretendem utilizar dos benefícios disponibilizados. Outro questionamento da pesquisa foi se as empresas tiveram necessidade de buscar recursos emprestados no período de março a novembro de 2020. Obteve-se que 29,52\% delas já tiveram necessidade de buscar empréstimo nesse período, 60,65\% informaram que não necessitaram de novos empréstimos e 9,83\% não quiseram responder. Observou-se que, mesmo com a crise provocada pela pandemia, a maior parte das empresas não necessitaram de novos empréstimos, o que demonstra que estavam com as finanças em equilíbrio, porém uma parte significativa $(29,52 \%)$ contraiu novos empréstimos. Cabe destacar que, nesse período de crise decorrente da pandemia, o governo brasileiro disponibilizou programas emergenciais com o objetivo de minimizar o impacto da crise sobre as empresas, como suspensão temporária de dívidas públicas (impostos e financiamentos), criação de linhas de crédito especiais com taxas mais atrativas, realização de parcerias com instituições financeiras como as cooperativas de crédito, que apresentam opções mais competitivas (SEBRAE, 2020). 
Outro interesse da pesquisa foi saber se durante o período de pandemia houve alguma mudança nas ferramentas utilizadas pelas empresas para realizar a gestão financeira (Gráfico 2). Nesta pergunta os respondentes puderam marcar mais de uma opção. Os resultados indicaram que as ferramentas mais utilizadas eram o controle do fluxo de caixa $(15,70 \%)$, o controle de contas a pagar e a receber $(11,57 \%)$, o controle de estoque $(9,09 \%)$, vendas a prazo no cartão $(7,44 \%)$, análise da necessidade de capital de giro $(6,61 \%)$, controle de custos $(5,79 \%)$, controle do prazo médio de pagamento e recebimento $(5,79 \%)$.

Apesar do índice de utilização das ferramentas continuarem muito baixos, identificou-se uma pequena mudança nos resultados do gráfico $2 \mathrm{em}$ relação ao gráfico 1 . Verificou-se um pequeno aumento na quantidade de empresas que utilizavam determinadas ferramentas, entre elas destacou-se o controle do fluxo de caixa, o controle de estoques, a análise do capital de giro, o cálculo do prazo médio de pagamento e recebimento e a utilização de software para controle de custos. A ferramenta que apresentou maior aumento na sua utilização foi a análise do capital de giro, que passou de 1,52\% para 6,61\%. A análise do capital de giro é uma ferramenta de extrema importância para assegurar a saúde financeira das empresas. De acordo com Assaf Neto e Lima (2014), o capital de giro são os recursos financeiros necessários para que a organização possa cumprir com suas obrigações tempestivamente e, portanto, a gestão ineficiente desses recursos pode levar o empreendimento a uma situação de insolvência e falência. Outra informação levantada pela pesquisa foi que, durante o período da pandemia, 27,86\% dos gestores financeiros procuraram treinamentos e consultorias na área financeira, porém a grande maioria $(72,13 \%)$ não teve interesse em se capacitar. O aumento na utilização da análise do capital de giro pode ter sido em decorrência da capacitação em finanças que conscientizou alguns gestores sobre a importância da sua utilização para preservar a saúde financeira da empresa.

Gráfico 2 - Ferramentas utilizadas na Gestão Financeira mediante a Pandemia.

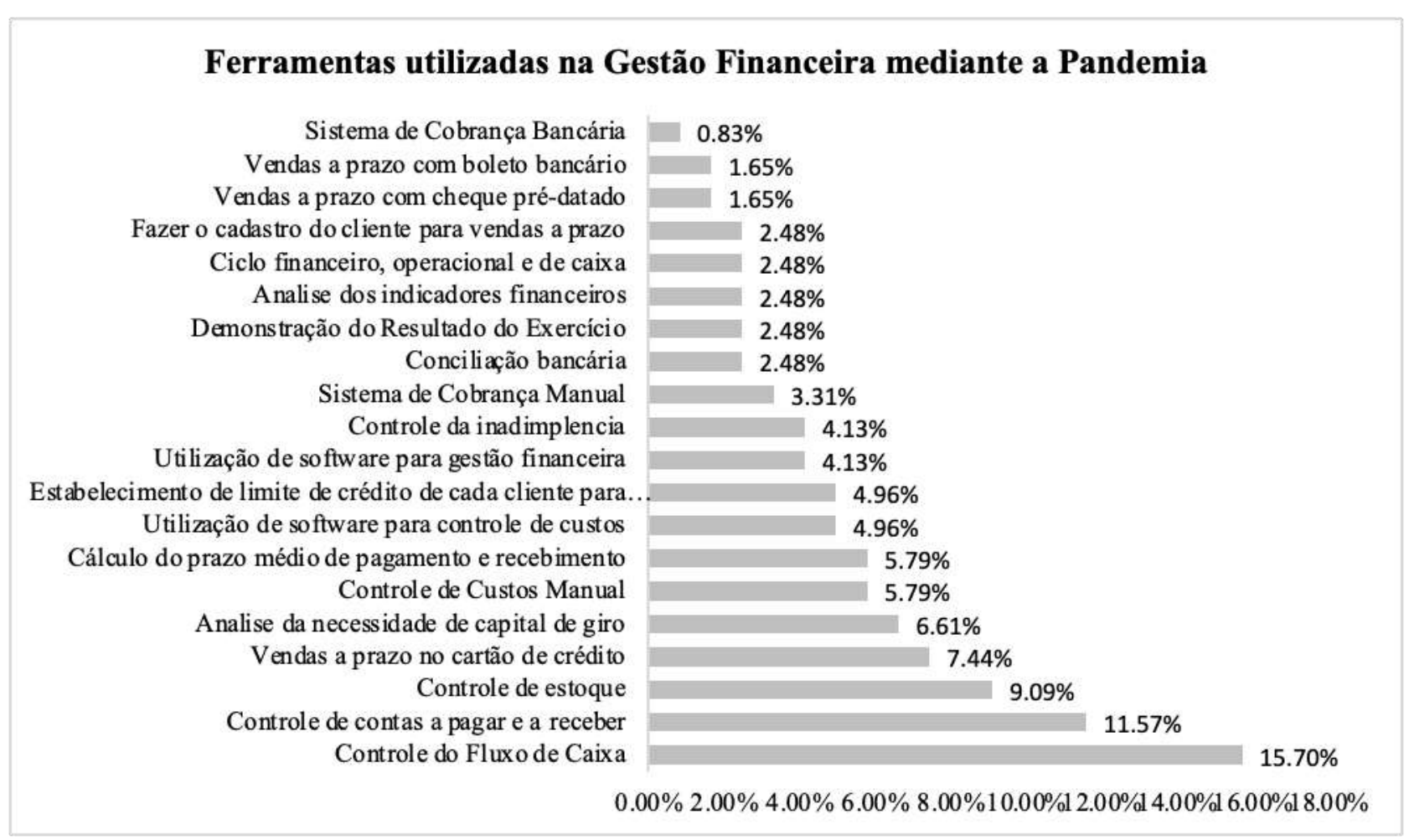

Fonte: Autores (2021).

Outro questionamento da pesquisa foi sobre o que melhorou na empresa nesse período de pandemia. Obteve-se que $24,81 \%$ expandiram o número de canais para atendimento ao cliente, para 18,05\% foi a maior visibilidade da marca nas redes virtuais, para $12,03 \%$ foi o aumento do faturamento, para $10,53 \%$ foi o aumento do portfólio de produtos e serviços oferecidos, 
para $9,77 \%$ foi a formação de uma reserva de emergência, para $9,02 \%$ foi o crescimento da base de clientes, para $6,02 \%$ foi a expansão da empresa, para outros $6,02 \%$ foi a contratação de mais funcionários e para 3,76\% foi a quitação de dívidas. Podese perceber que uma parte significativa das empresas souberam enxergar na crise uma oportunidade para melhorar, destacandose o aumento da quantidade de canais de atendimento ao cliente $(24,81 \%)$ e maior visibilidade nas redes sociais $(12,03 \%)$. A ampliação dos canais de atendimento, principalmente através das plataformas virtuais contribui para minimizar os riscos a que a micro e pequena empresa está exposta, uma vez que expande sua área de atuação, passando do atendimento local para o global.

Foi perguntado às empresas quais seriam as perspectivas de recuperação do seu segmento de atuação, afetado pela pandemia do COVI-19. 42,62\% responderam que acreditavam que o panorama melhorará por volta do segundo semestre de 2021, 24,59\% disseram que seria até junho de 2021, 14,75\% acreditavam que seria ainda no primeiro trimestre de 2021 e 18,03\% informaram não sabiam quando normalizaria. O presidente do Sebrae, Carlos Melles, defende que a recuperação do mercado para as micro e pequenas empresas está atrelado a liberação de crédito aliado a ações que estimulem a produtividade dos negócios (Ribeiro, 2021).

$\mathrm{Na}$ opinião das empresas pesquisadas, as medidas mais impactantes que contribuiriam para compensar os efeitos do coronavírus no negócio seria, primeiramente a redução de impostos e taxas na opinião de 50,62\%, para 25,93\% seria a redução das tarifas de água e luz e para $23,45 \%$ seria a liberação de empréstimos sem juros.

\section{Considerações Finais}

Este trabalho teve o objetivo de identificar os impactos da pandemia do COVID-19 na gestão das micro e pequenas empresas do setor varejista do município de Cláudio, localizado no Estado de Minas Gerais.

Os dados levantados pela pesquisa permitiram responder o problema e alcançar os objetivos propostos. As empresas pesquisadas eram de diversos ramos de atividade, com predominância do ramo de vestuário e atuavam no mercado entre 2 e 5 anos. Os gestores financeiros em sua maioria eram do gênero feminino, possuíam ensino médio completo e não tinham formação na área financeira.

Antes da pandemia do COVID-19 o faturamento das empresas estava em crescimento e a maioria pagava as contas em dia. Não era prática da maioria das empresas a utilização sistemática de ferramentas de gestão financeira, sendo que, entre os empreendimentos que faziam uso de algumas ferramentas, as mais utilizadas eram o controle de fluxo de caixa, o controle de contas a pagar e receber, o controle de custos, o controle de estoque e vendiam através do cartão de crédito.

Com a pandemia e a mudança do cenário, as organizações tiveram que se adaptar as orientações governamentais de combate ao Coronavírus, em função disso o faturamento diminuiu, a dificuldade de manter as contas em dia aumentou, para algumas empresas houve aumento do custo com pessoal, impostos, energia elétrica, entre outros. As ferramentas que eram utilizadas antes da pandemia continuaram a ser utilizadas durante esse período, porém por um número maior de empresas. A análise da necessidade de capital de giro, que era utilizada por poucas empresas passou a ser utilizada por uma quantidade bem maior.

Portanto, os impactos ocasionados pela crise decorrente da pandemia do novo coronavírus sobre a maioria das empresas pesquisadas foram negativos, entre eles destacam-se a queda no faturamento; a mudança na forma de funcionamento da empresa; o aumento dos gastos, principalmente com pessoal, energia elétrica, água e impostos; a demissão ou afastamento de funcionários, redução da jornada de trabalho e suspensão do contrato de trabalho; entre outros. Porém, para algumas o impacto foi positivo pois aumentaram os canais de atendimento, alcançaram maior visibilidade nas redes sociais, aumento no faturamento, entre outros. 
A principal limitação encontrada para realização da pesquisa foi a dificuldade no contato com as empresas pesquisadas e a falta de disponibilidade das mesmas para responder ao questionário. A sugestão para outros trabalhos é a realização de pesquisas com esta mesma abordagem em outros segmentos do mercado claudiense para comparação.

\section{Referências}

ADVFN Brasil (2020). Comércio Varejista. https://br.advfn.com/indicadores/comercio-varejista

Agência IBGE Notícias (2020). Vendas no varejo variam $-0,1 \%$ em dezembro e acumulam alta de $1,8 \%$ em 2019 . https://agenciadenoticias.ibge.gov.br/agencia-sala-de-imprensa/2013-agencia-de-noticias/releases/26856-vendas-no-varejo-variam-0-1-em-dezembro-eacumulam-alta-de-1-8-em-2019

Alvarenga, D. (2020). Impostos, tributos e contribuições: veja o que foi adiado, suspenso ou reduzido durante a pandemia. G1. Rio de Janeiro. https://g1.globo.com/economia/noticia/2020/04/15/impostos-tributos-e-contribuicoes-veja-o-que-foi-adiado-suspenso-ou-reduzido-durante-a-pandemia.ghtml

Antonik, L. R. (2016). Empreendedorismo: Gestão Financeira Para Micro e Pequenas Empresas. Books.

Assaf Neto, A. \& Silva, C. A. T. (2014). Administração do Capital de Giro. (4a ed.). Atlas.

Assaf Neto, A. \& Lima, F. G. (2014). Curso de Administração Financeira. (3a ed.). Atlas.

Ayer, F. (2019). Vendas no varejo estão estagnadas. Estado de Minas https://www.em.com.br/app/noticia/economia/2019/08/08/internas_economia,1075705/vendas-no-varejo-estao-estagnadas.shtml

Bomfim, R. (2020). O que se sabe até agora sobre o impacto do coronavírus no varejo- e as ações para comprar. Infomoney. https://www.infomoney.com.br/mercados/o-que-se-sabe-ate-agora-sobre-o-impacto-do-coronavirus-no-varejo-e-as-acoes-para-comprar/

Donato, C. (2012). O conceito do varejo e a importância da tomada de decisão! Administradores.com. [S. 1.]. João Pessoa. https://administradores.com.br/artigos/o-conceito-do-varejo-e-a-importancia-da-tomada-de-decisao

Estigarribia, J. et. al. (2020). O peso da dívida. Revista Exame. São Paulo, ano 22, n. 1213. https://exame.com/revista-exame/o-peso-da-divida/

Gil, A. C. (2008). Como elaborar projetos de pesquisa. (4a ed.). Atlas.

Gitman, L. J. (2010). Princípios da Administração Financeira. (12a ed.). Pearson Prentice Hall.

Global Entrepreneurship Monitor $\quad$ (2019). Empreendedorismo $\quad$ no $\quad$ Brasil https://ibqp.org.br/PDF\%20GEM/Relat\%C3\%B3rio\%20Executivo\%20Empreendedorismo\%20no\%20Brasil\%202019.pdf

Grupo Banco Mundial (2020). Covid-19 no Brasil: Impactos e Respostas de Políticas elicas. https://www.worldbank.org/pt/country/brazil/publication/covid-19-in-brazil-impacts-policy-responses

Hoji, M. (2014). Administração financeira e orçamentária: matemática financeira aplicada, estratégias financeiras, orçamento empresarial. (11a ed.). Atlas. Junqueira, G. (2018). Gestão Financeira no varejo: como tornar eficiente? Infovarejo. https://www.infovarejo.com.br/gestao-financeira-no-varejo

Kotler, P. \& Keller, K. L (2006). Administração de Marketing. Pearson Prentice Hall.

Kummer, A. A. et al. (2011). A utilização das ferramentas de Gestão Financeira nas empresas. Revista CAP Accounting and Management . Toledo, v. 2012, n. 5. http://revistas.utfpr.edu.br/pb/index.php/CAP/article/view/1540

Lima Filho, D. de O. et. al. (2006). Redes de Cooperação no Varejo Alimentar de Vizinhança: Percepções dos Associados. Gestão \& Produção. São Carlos, v.13, n.2, p.311-324, mai.-ago. 2006. https://www.scielo.br/pdf/gp/v13n2/31176.pdf

Machado, N. F. (2020). Impactos da Covid-19 evidenciados nas demonstrações financeiras das maiores Companhias Varejistas Brasileiras. https://repositorio.ufu.br/bitstream/123456789/31183/3/ImpactosCovid19.pdf

Mannarelli Filho, T. \& Mannarelli L.B. (2020). Posicionamento estratégico anterior e posterior a pandemia do Covid-19: um estudo de caso em empresa comercial de condicionador de ar no Brasil. Research, Society and Development, v. 9, n. 12. http://dx.doi.org/10.33448/rsd-v9i12.11059

Marion, J. C. (2009). Contabilidade Empresarial. (15a ed.). Atlas.

Oliveira, D. C. (2013). Como elaborar controles financeiros. Serviço Brasileiro de Apoio às Micro e Pequenas Empresas. https://www.sebrae.com.br/Sebrae/Portal\%20Sebrae/UFs/MG/Sebrae\%20de\%20A\%20a\%20Z/Mnaual\%20Participante\%202015\%20-

$\% 20$ COMO\%20ELABORAR\%20CONTROLES\%20FINANCEIROS.pdf

Prodanov, C. C. \& Freitas, E. C. de (2013). Metodologia do trabalho científico: método e técnicas de pesquisa e do trabalho acadêmico. (2a ed.). Feevale. https://www.feevale.br/Comum/midias/0163c988-1f5d-496f-b118-a6e009a7a2f9/E-book\%20Metodologia\%20do\%20Trabalho\%20Cientifico.pdf

Ribeiro, M. (2021). Sebrae quer mais crédito para pequeno negócio. Valor Investe. https://valorinveste.globo.com/mercados/brasil-epolitica/noticia/2021/01/11/sebrae-quer-mais-credito-para-pequeno-negocio.ghtml

Saleh, F. (2021). A História do varejo no século XIX. Audaces. https://audaces.com/a-historia-do-varejo-no-seculo-xix/ 
Research, Society and Development, v. 10, n. 6, e36910615303, 2021

(CC BY 4.0) | ISSN 2525-3409 | DOI: http://dx.doi.org/10.33448/rsd-v10i6.15303

Salomão, K. (2020). Esse é o maior desafio apontado pelas empresas na pandemia. Revista Exame. 06 mai. 2020. https://exame.com/negocios/os-desafios-dasempresas-na-pandemia-alem-de-manter-vendas/

Serviço Brasileiro de Apoio às Micro e Pequenas Empresas (2017). Perfil dos pequenos negócios. https://datasebrae.com.br/perfil-dos-pequenosnegocios/\#oqsao

Serviço Brasileiro de Apoio às Micro e Pequenas Empresas (2019). A importância do fluxo de caixa para a sobrevivência do seu negócio. https://www.sebrae.com.br/sites/PortalSebrae/ufs/ap/artigos/a-importancia-do-fluxo-de-caixa-para-a-sobrevivencia-do-seu-

negocio,818cfac4377af510VgnVCM1000004c00210aRCRD

Serviço Brasileiro de Apoio às Micro e Pequenas Empresas (2019). Análise da crise e impactos para os pequenos negócios. https://www.sebrae.com.br/Sebrae/Portal\%20Sebrae/UFs/ES/Sebrae\%20de\%20A\%20a\%20Z/RELAT\%C3\%93RIO\%20IMPACTO\%20COVID\%20-

$\%$ 20CORRETO.pdf

Serviço Brasileiro de Apoio às Micro e Pequenas Empresas (2020). Boletim de Impacto e Tendências Edição $n^{\circ}$ 07 (15/05/2020). https://m.sebrae.com.br/sites/PortalSebrae/sebraeaz/leia-os-boletins-de-mercado-de-cada-setor-e-atualize-a-suaempresa,de5f974198962510VgnVCM1000004c00210aRCRD

Serviço Brasileiro de Apoio às Micro e Pequenas Empresas (2020). O Impacto da pandemia de corona vírus nos Pequenos Negócios - $2^{a}$ edição https://www.sebrae.com.br/Sebrae/Portal\%20Sebrae/Imagens\%20SebraeNA/Pesquisa\%20O\%20impacto\%20do\%20Coronav\%C3\%ADrus\%20nos\%20pequen os $\% 20$ neg\%C3\%B3cios\%20-\%20Pesquisa\%20completa\%20\%20n\%C2\%BA2\%20(09042020.pdf

Serviço Brasileiro de Apoio às Micro e Pequenas Empresas (2020). Pequenos negócios em números. https://m.sebrae.com.br/sites/PortalSebrae/ufs/sp/sebraeaz/pequenos-negocios-em-numeros,12e8794363447510VgnVCM1000004c00210aRCRD

Serviço Brasileiro de Apoio às Micro e Pequenas Empresas (2020). Pequenos negócios já representam $30 \%$ do Produto Interno Bruto do país. https://www.sebrae.com.br/sites/asn/uf/NA/pequenos-negocios-ja-representam-30-do-produto-interno-bruto-dopais,7b965c911da51710VgnVCM1000004c00210aRCRD

Serviço Brasileiro de Apoio às Micro e Pequenas Empresas (2020). Pequenos negócios pretendem investir para estimular vendas. http://www.agenciasebrae.com.br/sites/asn/uf/NA/pequenos-negocios-pretendem-investir-para-estimular-

vendas,d31b13c8bbfc0710VgnVCM1000004c00210aRCRD

Serviço Brasileiro de Apoio às Micro e Pequenas Empresas (2020). Sebrae identifica setores mais afetados pela crise do Coronavírus. http://www.agenciasebrae.com.br/sites/asn/uf/NA/sebrae-identifica-setores-mais-afetados-pela-crise-docoronavirus,ec0444e2adee0710VgnVCM1000004c00210aRCRD\#prettyPhoto

Serviço Brasileiro de Apoio às Micro e Pequenas Empresas (2021).Micro e pequenas empresas geram $27 \%$ do PIB do Brasil. https://www.sebrae.com.br/sites/PortalSebrae/ufs/mt/noticias/micro-e-pequenas-empresas-geram-27-do-pib-dobrasil,ad0fc70646467410VgnVCM2000003c74010aRCRD

Serviço Brasileiro de Apoio às Micro e Pequenas Empresas (2021). Pequenos negócios em segmentos mais vulneráveis à crise do Coronavirus. https://datasebrae.com.br/coronavirus/

Viana, Humberto (2019). Os desafios do Varejo. Varejo S.A. http://revistavarejosa.com.br/os-desafios-do-var 